\title{
USO DE FOTOGRAFIAS AÉREAS COLORIDAS 35 mm NA AVALIAÇÃO DE PRODUTIVIDADE DE GRÃOS
}

\section{JOÃO C. DE ARAÚJO ${ }^{1}$, JOSÉ P. MOLIN ${ }^{2}$, CARLOS A. VETTORAZZI ${ }^{3}$}

RESUMO: Este trabalho foi realizado em duas lavouras monitoradas intensivamente como áreaspiloto de agricultura de precisão. Vários dados estão sendo obtidos como mapeamento de produtividade, levantamentos de propriedades físicas e químicas do solo, pragas, doenças e plantas invasoras, bem como fotografias aéreas coloridas no formato $35 \mathrm{~mm}$. As fotografias receberam orientação por bandeiras georreferenciadas em solo com DGPS para a correção geométrica das imagens e, após selecionadas, foram digitalizadas por meio de scanner. Foram, então, analisados os coeficientes de determinação entre o valor digital das imagens e a produtividade. Os coeficientes de determinação para as duas áreas, em todos os períodos analisados, apresentaram valores baixos, não havendo correspondência entre os valores digitais das imagens e as produtividades.

PALAVRAS-CHAVE: agricultura de precisão, variabilidade espacial, sensoriamento remoto.

\section{USE OF COLOR AERIAL PHOTOS 35 mm ON GRAIN YIELD ESTIMATION}

SUMMARY: Precision Agriculture is being used as an alternative for improving production in developed countries. In Brazil it is just starting and research contribution is fundamental in the process of its adoption. This work aimed to study the potential use of $35 \mathrm{~mm}$ color aerial photos to predict yield in grain crops. Some fields are been intensivelly monitored and data are been taken, like yield maps, physical and chemical soil properties, weeds, diseases and pests and also $35 \mathrm{~mm}$ color aerial photos. The photos were georeferenced by ground flags located with DGPS. After selecting the best photos, they were scanned. The images and yield maps were processed and the regressions between images and yield were analized. Low determination coefficients were obtained in all cases, showing little potential for this kind of information on predicting yield variability in the field.

KEYWORDS: precision agriculture, spacial variability, remote sensing.

\section{INTRODUÇÃO}

A agricultura de precisão é uma prática que vem gerando muitos questionamentos. No Brasil, dispõe-se de pouca informação, sendo inevitáveis as especulações sobre o assunto. COSTA \& SANTOS (1997) comentam que, historicamente, as técnicas de produção agropecuária têm sido desenvolvidas para serem implementadas em grandes áreas, assumindo que essas sejam unidades homogêneas. Segundo STEVE \& MILAR (1997), a agricultura de precisão surgiu visando a adequar a administração agrícola em relação às condições variadas encontradas nos campos. Isso tornou-se possível recentemente, devido ao desenvolvimento de tecnologias que permitem monitorar e medir essas variações.

A agricultura de precisão propõe que o tratamento localizado dos pontos do terreno pode maximizar o uso da terra e de insumos agrícolas, aumentando a produtividade e diminuindo o gasto com insumos. Tal prática diminui a toxidez causada pelo excesso de algumas substâncias que são empregadas na produção agrícola, reduzindo assim a pressão sobre o meio ambiente.

\footnotetext{
${ }^{1}$ Eng ${ }^{\circ}$ Agrônomo, Doutorando, ESALQ/USP, Piracicaba - SP, Fone: (0XX19) 3429.4165, e-mail: jcaraujo@ carpa.ciagri.usp.br

${ }^{2}$ Eng $^{\mathrm{o}}$ Agrícola, Professor da ESALQ/USP, Fone: (OXX19) 3429.4165, Ramal 212, Piracicaba - SP.

${ }^{3}$ Eng ${ }^{0}$ Agrônomo, Professor da ESALQ/USP, Fone: (0XX19) 3429.4165, Ramal: 203, Piracicaba - SP.

Recebido pelo Conselho Editorial em: 12-12-2000

Aprovado pelo Conselho Editorial em: 23-7-2004
} 
Essa tecnologia está embasada na análise da variabilidade espacial dos fatores de produção, especialmente do solo. A tecnologia deve ser, no entanto, validada com base em análises que provem as suas vantagens e desvantagens. Dentro desse contexto, o sensoriamento remoto tem potencial na detecção da variabilidade espacial, auxiliando o agricultor na tomada de decisão de utilizar ou não tais técnicas. Segundo SCHUELLER (1992), o conhecimento da variabilidade espacial da produção das culturas agrícolas é a informação mais importante nos sistemas de produção utilizando agricultura de precisão.

Dentre as diferentes possibilidades de mapeamento dessa variabilidade, o sensoriamento remoto tem se mostrado como uma das técnicas mais promissoras, porém ainda carente de desenvolvimento. SENAY et al. (1998) comentam que estudos têm demonstrado que o sensoriamento remoto se relaciona intimamente com a agricultura de precisão, porém é necessário o desenvolvimento de técnicas para extrair informações pertinentes das imagens. TAYLOR et al. (1997) apontaram que fotografias aéreas podem ser utilizadas com sucesso para mapear a distribuição do potencial de produtividade para grãos, quando utilizada a técnica de determinação de índice de vegetação para a realização da análise.

Este trabalho foi realizado em duas áreas-piloto para agricultura de precisão, onde se buscam respostas para as várias questões que cercam o assunto. Para tanto, desenvolveu-se uma metodologia para explorar o potencial de informações contidas em fotografias aéreas coloridas $35 \mathrm{~mm}$, de lavouras em várias fases do desenvolvimento vegetativo das culturas da soja e do milho. Tais informações foram confrontadas com os mapas de produtividade das lavouras, para a verificação do coeficiente de determinação entre ambas.

\section{MATERIAL E MÉTODOS}

As áreas envolvidas no trabalho fazem parte de um projeto em que estão sendo monitorados vários talhões para o correto entendimento dos fenômenos relacionados à variabilidade espacial da produtividade. A área 1 situa-se no município de Pirassununga - SP, entre os paralelos $21^{\circ} 57^{\prime}$ e $21^{\circ} 58^{\prime}$ de latitude sul e os meridianos $47^{\circ} 27^{\prime}$ e $47^{\circ} 28^{\prime}$ de longitude oeste. A área de estudos é composta de aproximadamente uma quarta parte de um pivô central, com uma área de 17,9 ha. O clima local, segundo o sistema de Köeppen, é do tipo Cwa, mesotérmico de inverno seco, em que a temperatura média é de $22^{\circ} \mathrm{C}$, a temperatura média do mês mais frio é de $18^{\circ} \mathrm{C}$ (julho) e a do mês mais quente (fevereiro) é de $24^{\circ} \mathrm{C}$. O índice pluviométrico médio local é de $1.340 \mathrm{~mm}^{\mathrm{ano}}{ }^{-1}$.

A área 2 está situada no município de Campos Novos Paulista - SP, entre os paralelos $22^{\circ} 07^{\prime}$ e $22^{\circ} 08^{\prime}$ de latitude sul e os meridianos $50^{\circ} 08^{\prime}$ e 50 $09^{\circ}$ de longitude oeste, com uma área de 22,1 ha. $\mathrm{Na}$ região de Assis, a qual representa as condições climáticas de Campos Novos Paulista, a temperatura média anual é de $22,3^{\circ} \mathrm{C}$, sendo a temperatura média do mês mais frio de $17,7^{\circ} \mathrm{C}$ (julho) e a do mês mais quente (fevereiro) de $25,2^{\circ} \mathrm{C}$. A precipitação pluvial apresenta índice anual médio de $1.468 \mathrm{~mm}$, com chuvas concentradas entre os meses de setembro a março. O tipo climático local, segundo o sistema de Köeppen, é Cwa transicional para Cfa.

$\mathrm{Na}$ área 1 (Pirassununga), as safras de milho eram cultivadas com o sistema de semeadura convencional e sob o regime de sequeiro, até 1997. Na safra analisada no trabalho (1998-1999), foi cultivado milho irrigado, por pivô-central, em sistema de semeadura direta. Na área 2 (Campos Novos Paulista), foi implantado o sistema de plantio direto na safra 1995-1996. Essa área apresenta um sistema de rotação de culturas, em que são cultivados soja, milho e culturas de inverno para cobertura do solo. Na safra analisada no trabalho (1998-1999), foram cultivados soja no verão e milho safrinha na seqüência. 
As fotografias foram obtidas como uma das etapas do projeto de monitoramento das áreas-piloto de agricultura de precisão, em que foram coletados dados para a realização deste trabalho. A câmara fotográfica utilizada foi uma Canon MC Micro Compact $35 \mathrm{~mm}$.

As fotos foram obtidas sem controle rígido de altura de vôo, uma vez que o critério adotado foi a busca de enquadramento da área de estudos em uma única fotografia, evitando a necessidade de mosaicagem. A conversão das fotografias para o formato digital foi realizada com o uso de scanner com resolução de 150 dpi (padrão). O programa "Idrisi for Windows", versão 2.0, foi utilizado para a transformação das fotografias aéreas em planilhas de valor digital de imagem, além de ser utilizado na correção geométrica das mesmas.

O coeficiente de determinação entre valor digital de imagem e produtividade para a área 1 (Pirassununga) foi realizado por meio de uma análise temporal, em que foram consideradas as melhores fotografias obtidas em uma sequiência de quatro datas ao longo do ciclo do milho (25-111998, 14-12-1998, 27-12-1998 e 15-1-1999). Na área 2 (Campos Novos Paulista), foram utilizadas fotografias das culturas da soja e do milho, visando a verificar a diferença existente no emprego do método em culturas distintas em uma mesma área. No caso da cultura da soja, foram analisadas fotografias obtidas no dia 12-2-1999 e, para a cultura do milho, foi analisada a fotografia obtida no dia 1-. -7-1999.

Os mapas de produtividade foram gerados a partir dos dados obtidos pelos monitores de colheita instalados nas colhedoras. O mapa da área 1 foi obtido utilizando-se de uma colhedora "John Deere 9510", equipada com um monitor de produtividade "GreenStar". Os mapas da área 2 foram obtidos utilizando-se de uma colhedora "New Holland TC 57", equipada com monitor de produtividade "RDS Ceres 2".

Inicialmente, esses dados foram tratados para eliminar valores de produtividade pouco prováveis. Estabeleceu-se que, para a produtividade do milho e da soja, seriam validados, respectivamente, valores superiores a $1 \mathrm{t} \mathrm{ha}^{-1}$ e $0,5 \mathrm{t} \mathrm{ha}^{-1}$. Como limite superior, foi estabelecido o dobro da produtividade média encontrada para ambas as culturas. Além disso, foram removidos todos os dados pontuais com problemas de localização. Na sequiência, procedeu-se à interpolação para a geração dos mapas utilizando-se do programa "SSToolbox", um sistema de informação geográfica (SIG) personalizado para agricultura de precisão.

O processo de correção geométrica das fotografias necessitou de alguns pontos de controle georreferenciados com um receptor de GPS “Omnistar” com correção diferencial via satélite também "Omnistar", denominados de bandeiras. Essas bandeiras foram constituídas de lonas de $4 \mathrm{~m}^{2}$, com coloração laranja, dispostas na área a ser fotografada. Foi estipulado como fator limitante para a correção geométrica o erro máximo de $5 \mathrm{~m}$. Esse erro variou de acordo com a inclinação da fotografia em relação ao terreno e número de bandeiras utilizadas no processo. Foram utilizadas de quatro a oito bandeiras na área 1 e de seis a oito bandeiras na área 2.

De posse dos valores da longitude, latitude e valor digital de imagem, para cada pixel, foram analisadas formas de exportação desses dados para o programa "SSToolbox". O formato de exportação utilizado foi o "Arcinfo", uma das opções de exportação disponíveis no programa "IDRISI", que permitiu a exportação desses dados em forma de planilha.

Os valores digitais de cada pixel (menor ponto de resolução da imagem) foram interpolados por meio do método "vizinho mais próximo", mesmo método utilizado na confecção dos mapas de produtividade. Por interpolação, as fotografias foram convertidas em valor digital de imagem em células de $5 \mathrm{~m}$ x $5 \mathrm{~m}\left(25 \mathrm{~m}^{2}\right)$ e $10 \mathrm{~m}$ x $10 \mathrm{~m}\left(100 \mathrm{~m}^{2}\right)$. Cada célula passou a ter um par de valores de coordenadas e valor digital, o qual variou de 0 a 255. Esses valores foram agrupados em cinco classes para a representação nos mapas de valor digital. Para a construção dessas classes, foi utilizado o 
critério de "áreas iguais", disponível no programa "SSToolbox". Esse parâmetro proporcionou uma visualização mais apurada da distribuição dos "pixels" na figura.

As coordenadas utilizadas no trabalho foram transformadas para o sistema (UTM) "Universal Transverso of Mercator", seguindo o sistema das coordenadas retangulares. No SIG, os mapas de produtividade e valor digital de imagem foram sobrepostos, resultando em células com coordenadas, valor digital de imagem e produtividade. Esses dados foram utilizados para a determinação do coeficiente de determinação no programa "Excel".

A análise referente à fotografia obtida no dia 12-2-1999 foi subdividida em classes de acordo com o valor digital de imagem e a produtividade. Foram utilizados três intervalos considerando-se o valor digital de imagem. O primeiro, com valores entre 65 e 110; o segundo, com valores entre 140 e 180 , e o terceiro, com valores entre 190 e 250 . Para a produtividade, foi selecionado o intervalo entre 0,5 e $3,0 \mathrm{t} \mathrm{ha}^{-1}$.

\section{RESULTADOS E DISCUSSÃO}

A utilização de fotografias aéreas sem o controle da altura do vôo foi satisfatória na realização do trabalho. O critério de obtenção das fotografias, quando a área estivesse enquadrada, resultou em imagens que se adequaram perfeitamente aos objetivos propostos. A utilização de bandeiras para a correção geométrica mostrou-se um método eficiente. $\mathrm{Na}$ área 1 (Pirassununga), as diversas fotografias obtidas apresentaram erros da ordem de $0,2 \mathrm{~m}$ a $0,3 \mathrm{~m}$. O georreferenciamento das fotos da área 2 (Campos Novos Paulista) apresentou erros variando entre 0,5 m a 1,3 m. Esse método de correção geométrica apresenta a desvantagem de ser trabalhoso, pois exige a distribuição e o georreferenciamento das bandeiras no campo. Uma alternativa seria utilizar pontos naturais identificáveis nas fotografias, como, por exemplo, cruzamento de estradas, carreadores e vértices da área.

Nas imagens digitalizadas, as bandeiras foram facilmente visualizadas, devido ao seu destaque em relação à cor da vegetação. Observou-se que poderiam ser utilizadas bandeiras de dimensões inferiores às utilizadas neste trabalho, sugerindo-se dimensões de até $1 \mathrm{~m}^{2}$, somente para a região perimetral da área, sem prejuízo na visualização dos pontos. Da mesma forma, em análises temporais de uma mesma área, as bandeiras podem ser colocadas na mesma posição para toda a sequiência de fotografias, facilitando o processo de reconhecimento e georreferenciamento das bandeiras. Na Figura 1, ilustram-se exemplos de mapas de produtividade e valor digital utilizados.

As análises entre valor digital de imagem e produtividade para a área 1 (Pirassununga) foram realizadas com 7.231 pontos e 1.835 pontos para células de $25 \mathrm{~m}^{2}$ e $100 \mathrm{~m}^{2}$, respectivamente. $\mathrm{Na}$ Figura 2, ilustram-se as análises obtidas no trabalho para células de $25 \mathrm{~m}^{2}$, na qual são apresentadas as linhas de tendência e os coeficientes de determinação.

Na Figura 3, ilustram-se as análises obtidas para células de $100 \mathrm{~m}^{2}$, na qual são apresentadas as linhas de tendência e coeficientes de determinação.

Em toda análise temporal, foram encontrados valores digitais correspondentes a valores distintos de produtividade e, na maioria dos casos, essa variação abrangia desde a produtividade mínima até a máxima. Esse fato descarta a hipótese de associação entre um valor digital de imagem a uma produtividade ou intervalo limitado de valores de produtividade.

As análises para a área 2 (Campos Novos Paulista) foram realizadas para as culturas de soja e milho, com 9.148 e 2.356 pontos para células de $25 \mathrm{~m}^{2}$ e $100 \mathrm{~m}^{2}$, respectivamente. Na Figura 4 , ilustram-se as dispersões de pontos para a cultura da soja com foto obtida no dia 12-2-1999, sendo também apresentados as linhas de tendência e os coeficientes de determinação. 


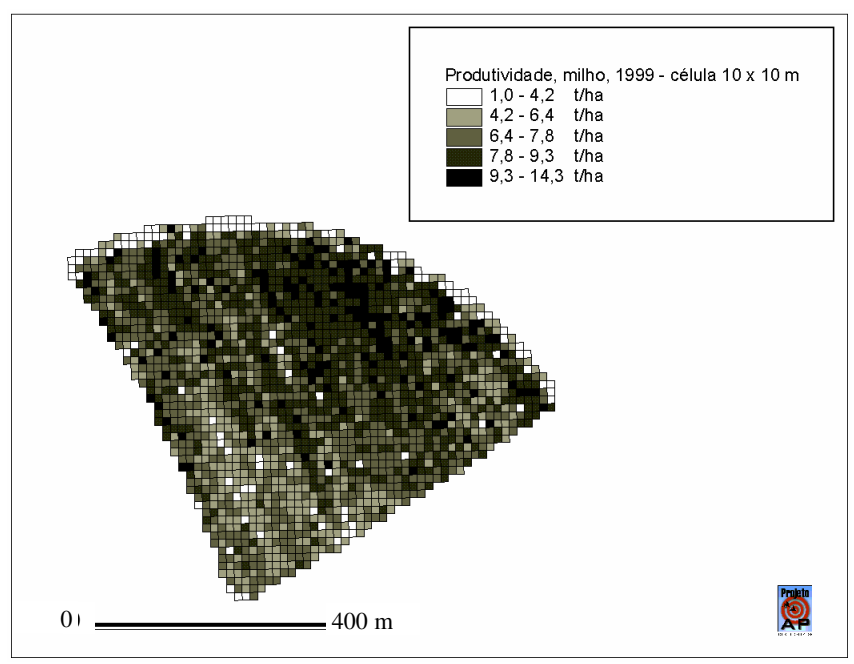

(a)

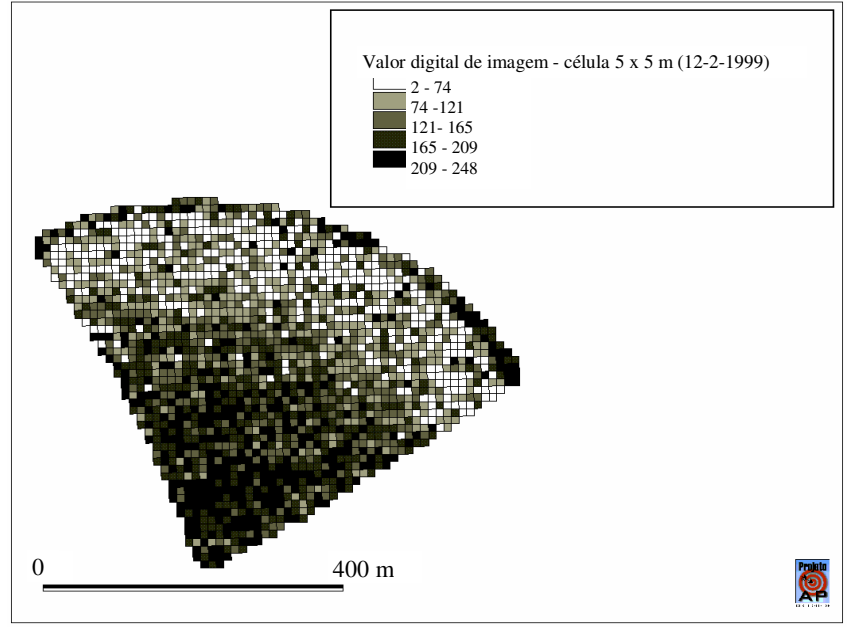

(c)

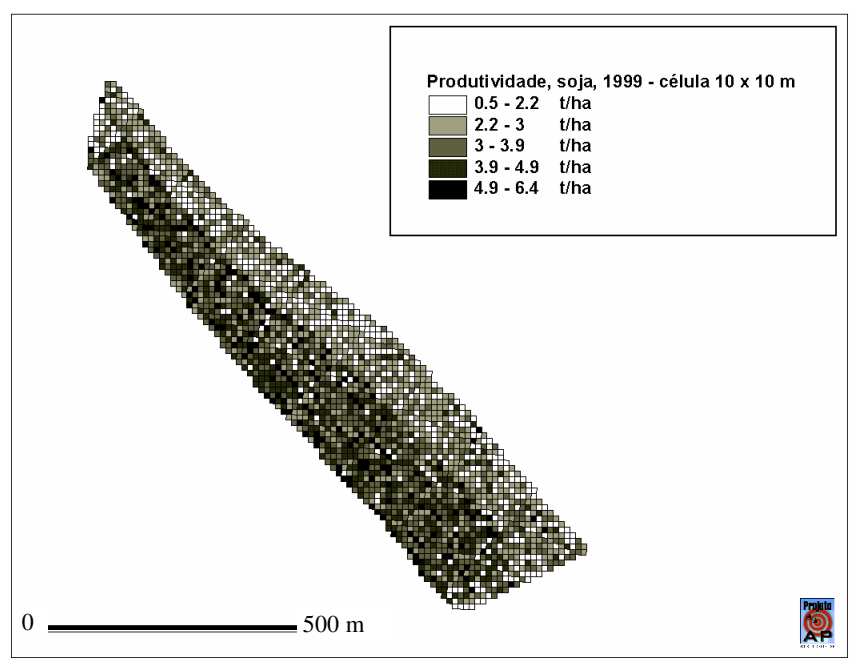

(b)

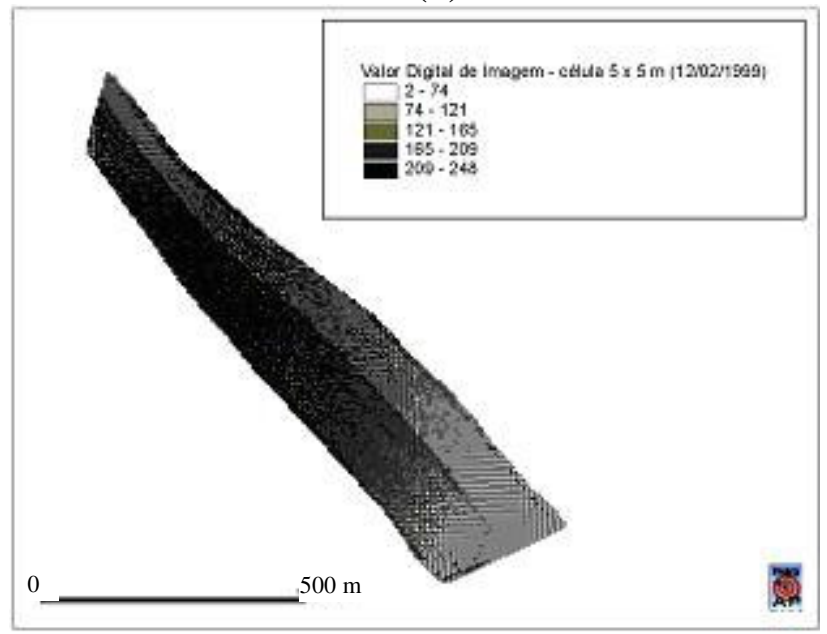

(d)

FIGURA 1. (a) Produtividade do milho, células de $100 \mathrm{~m}^{2}$, referente à área 1 (Pirassununga - SP); (b) produtividade da soja, células de $100 \mathrm{~m}^{2}$, referente à área 2 (Campos Novos Paulista SP); (c) valor digital de imagem, células de $100 \mathrm{~m}^{2}$, referente à área 1 (Pirassununga - SP) em foto obtida no dia 15-1-1999 para a cultura do milho, e (d) valor digital de imagem, células de $25 \mathrm{~m}^{2}$, referente à área 2 (Campos Novos Paulista - SP) obtida no dia 12-21999 para a cultura da soja. 


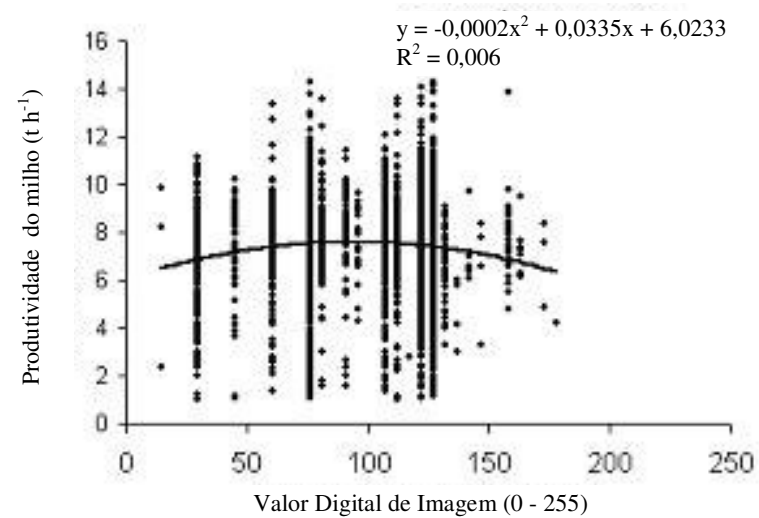

(a)

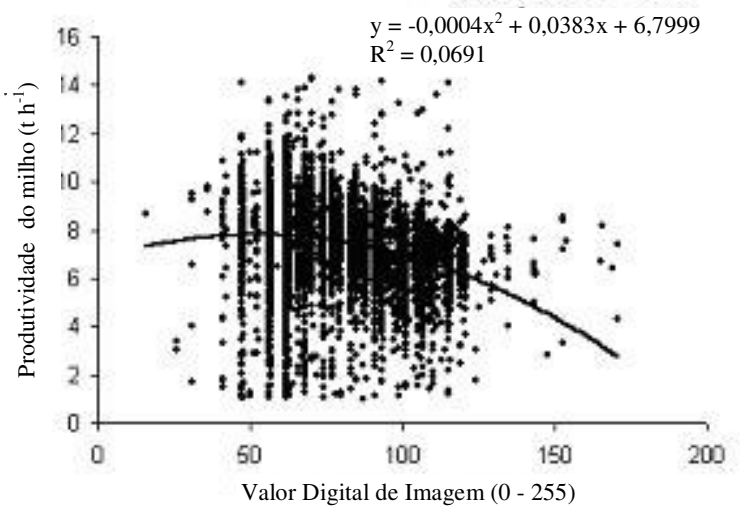

(c)

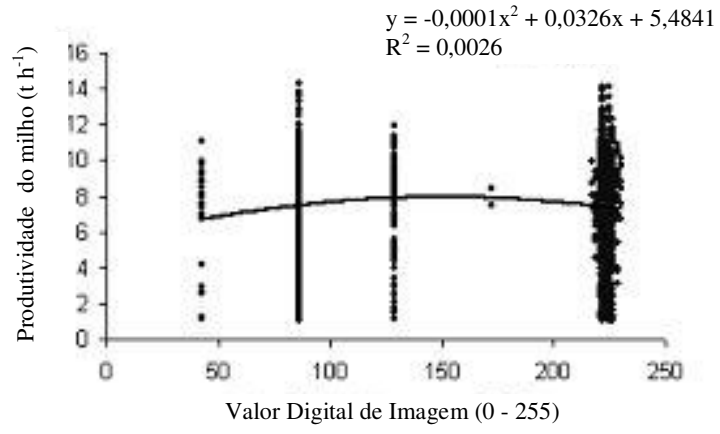

(b)

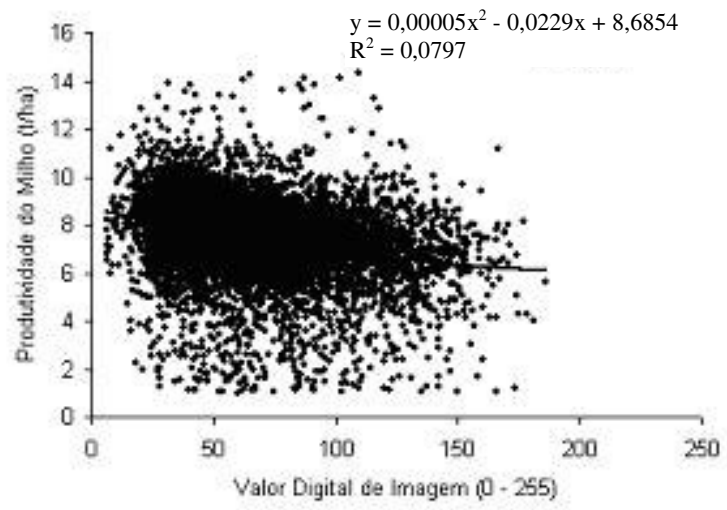

(d)

FIGURA 2. (a) Coeficiente de determinação entre o valor digital de imagem e produtividade da área 1 (Pirassununga) para a cultura do milho com células de $25 \mathrm{~m}^{2}$ e fotos obtidas nos dias: 2511-1998; (b) 14-12-1998; (c) 27-12-1998, e (d) 15-1-1999.

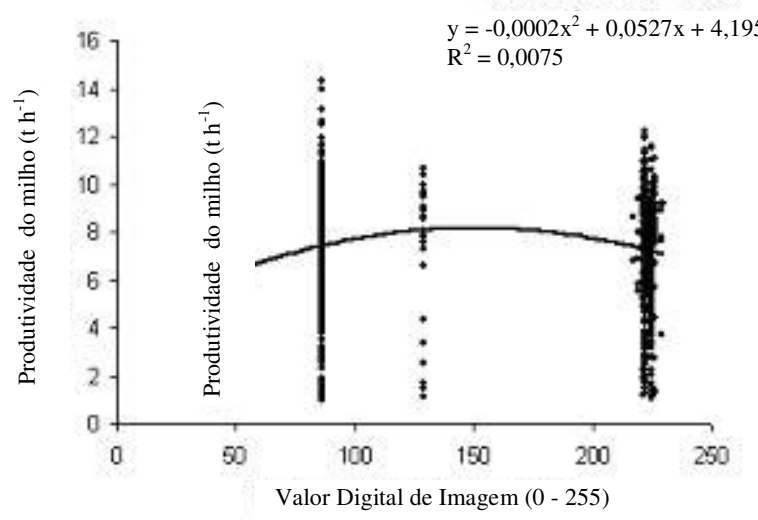

(a)

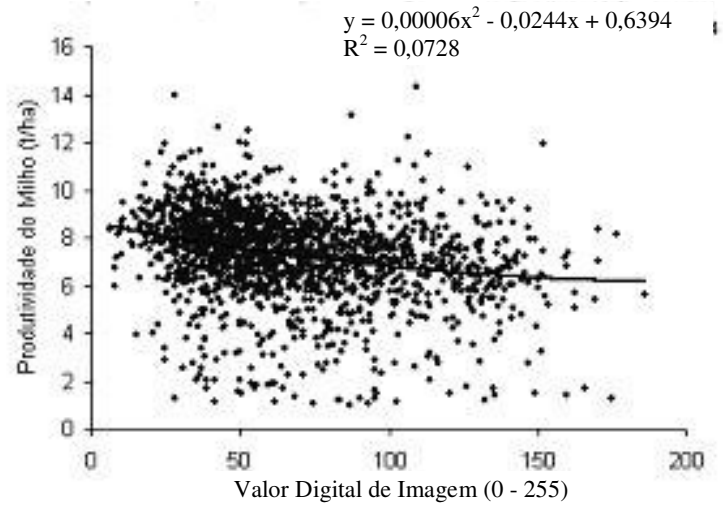

(b)

FIGURA 3. (a) Análises entre valor digital de imagem e produtividade da área 1 (Pirassununga) para a cultura do milho com células de $100 \mathrm{~m}^{2}$ e fotos obtidas nos dias: 14-12-1998 e (b) 15-1-1999. 


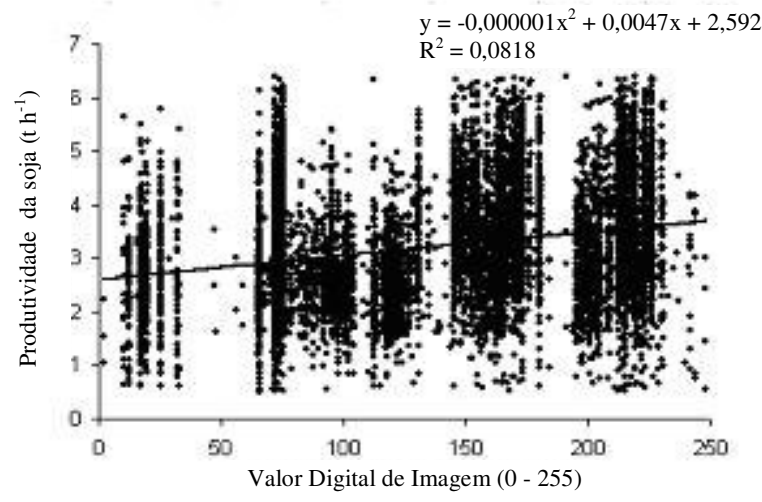

(a)

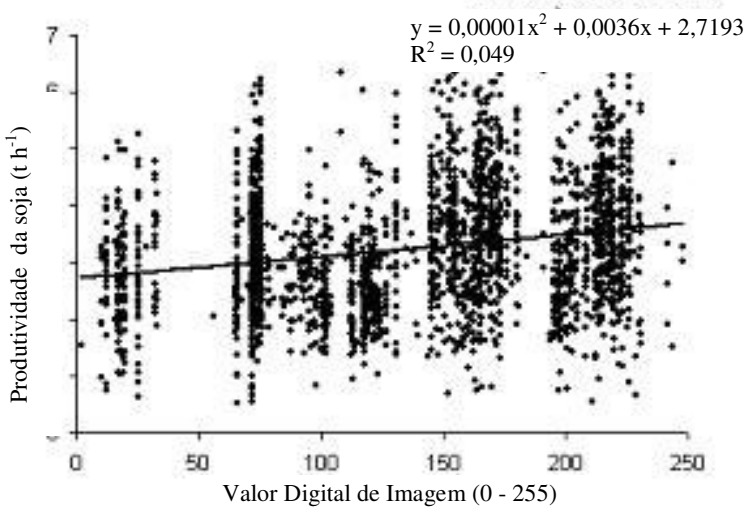

(b)

FIGURA 4. (a) Análise entre valor digital de imagem e produtividade da área 2 (Campos Novos Paulista) para a cultura do milho e foto obtida no dia 12-2-1999: com células de $25 \mathrm{~m}^{2}$ e (b) com células de $100 \mathrm{~m}^{2}$.

A análise para a imagem do dia 12-2-1999 apresentou a distribuição dos pontos de forma aleatória com valor de coeficiente de determinação $\left(\mathrm{r}^{2}\right)$ igual a 0,061 e 0,049 , para $25 \mathrm{~m}^{2}$ e $100 \mathrm{~m}^{2}$, respectivamente, valores considerados muito baixos.

Na área 2 (Campos Novos Paulista), para a cultura da soja, safra 1999, houve uma classificação natural da produtividade em duas zonas, devido ao fato de que a semeadura foi realizada em épocas diferentes. Mesmo com a ocorrência desse fato, não houve incremento no coeficiente de determinação. Nas duas zonas formadas naturalmente, os valores digitais de imagem corresponderam a valores muito variados de produtividade.

A distribuição dos pontos, naturalmente, formou algumas classes. A análise de algumas dessas classes são apresentadas na Figura 5, em que foram utilizadas classes de acordo com o valor digital da imagem e produtividade.

Nesse estudo por classes, no qual as análises foram realizadas com menor número de pontos, pode-se verificar que as mesmas permaneceram muito baixas.

As análises realizadas para a cultura do milho estão ilustradas na Figura 6. Nesse caso, ocorreu a diminuição do valor do coeficiente de determinação de 0,005 (células de $25 \mathrm{~m}^{2}$ ) para 0,002 (células de $100 \mathrm{~m}^{2}$ ), sendo que a tendência de distribuição dos pontos permaneceu a mesma.

A técnica desenvolvida apresentou valores de coeficiente de determinação baixos para todas as análises realizadas e em todas as situações. Em toda a sequiência de análises, não houve coeficiente de determinação significativo entre valor digital de imagem e produtividade. O maior valor de coeficiente de determinação foi igual a $\mathrm{r}^{2}=0,079 \mathrm{e} \mathrm{r}^{2}=0,060$, para as áreas 1 e 2, respectivamente, ambos os valores considerados inexpressivos.

As fotografias aéreas, como foram obtidas e analisadas, não têm utilidade na previsão de produtividade, não sendo relevante a época de obtenção da fotografia para as culturas da soja e do milho, com características morfológicas totalmente diferentes. Tal fato comprova que as fotografias aéreas $35 \mathrm{~mm}$, no espectro visível, dificilmente podem ser utilizadas para a estimativa de produtividade dessas culturas. 


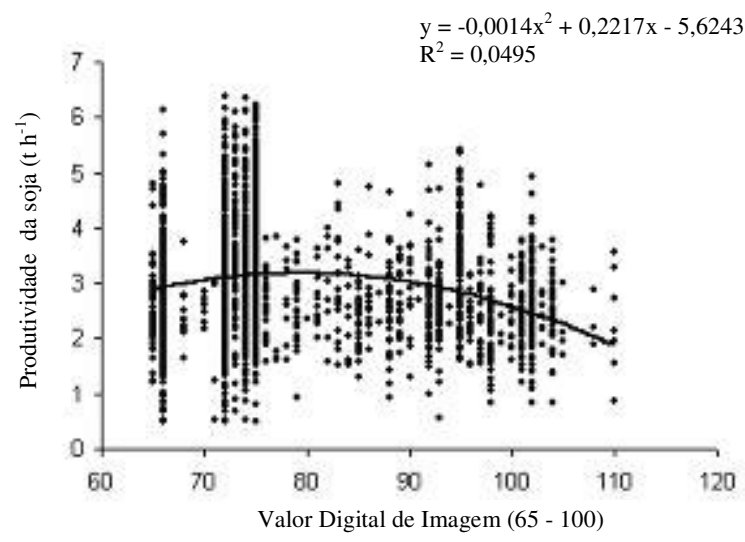

(a)

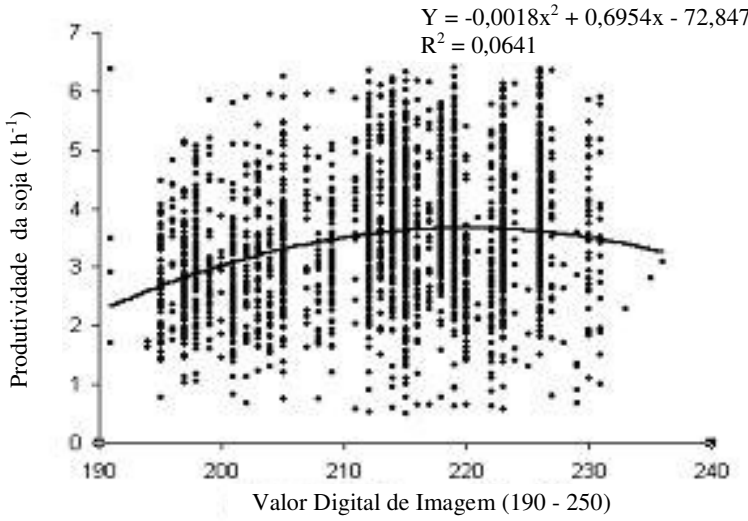

(c)

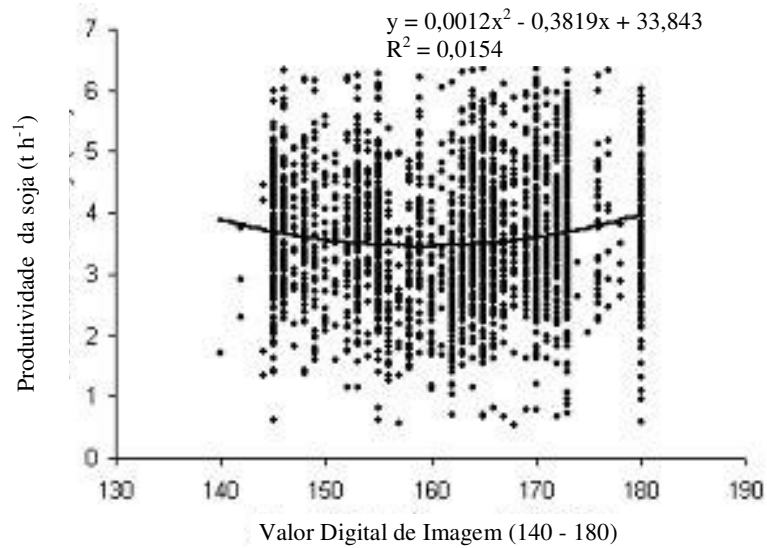

(b)

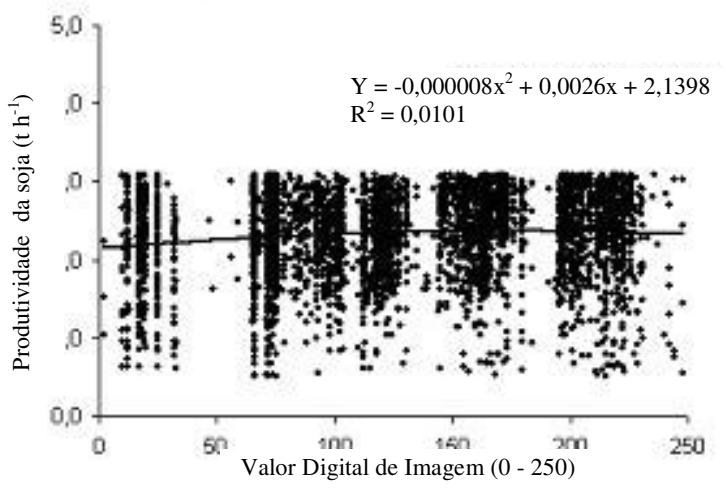

(d)

FIGURA 5. (a) Análise entre valor digital de imagem e produtividade, área 2 (Campos Novos Paulista), para a cultura da soja, em foto obtida no dia 12-2-1999, classificada de acordo com o valor digital de imagem: 65 a 110; (b) 140 a 180; (c) 190 a 250, e (d) classificada de acordo com a produtividade, de 0,5 a $3,0 \mathrm{t} \mathrm{ha}^{-1}$.

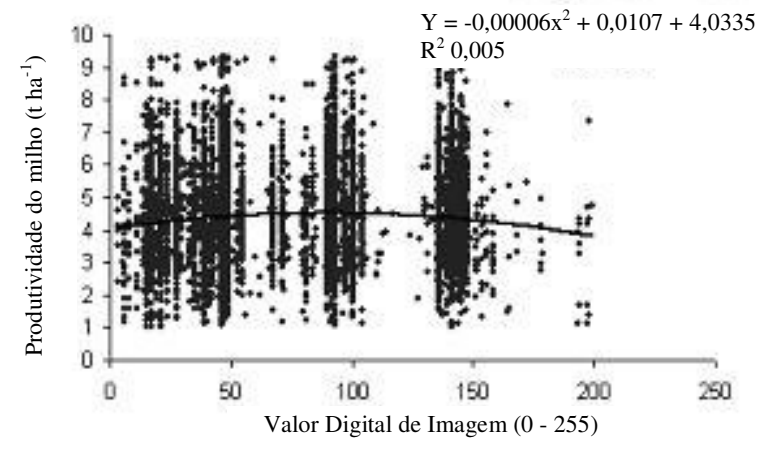

(a)

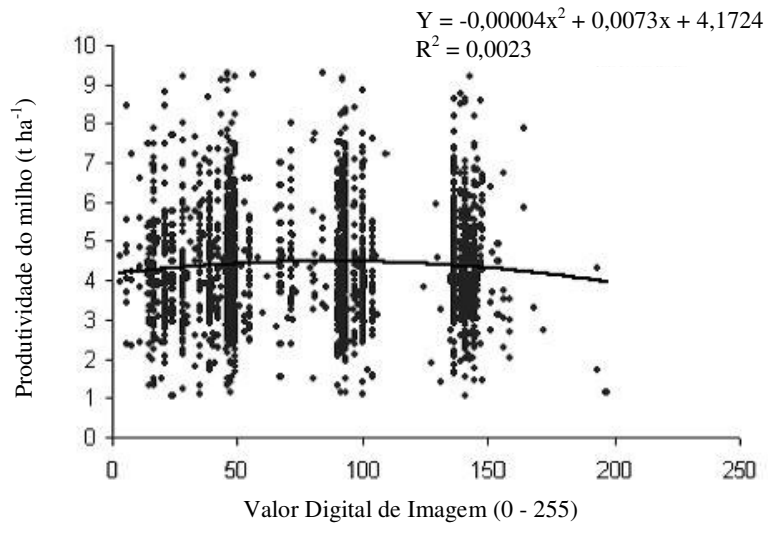

(b)

FIGURA 6. (a) Análise entre o valor digital de imagem e produtividade da área 2 (Campos Novos Paulista) para a cultura do milho e fotos obtidas no dia 1ํ-7-1999: com células de $25 \mathrm{~m}^{2} \mathrm{e}$ (b)com células de $100 \mathrm{~m}^{2}$.

O coeficiente de determinação entre as produtividades de grãos e os valores digitais das imagens foram baixos, resultando valores semelhantes aos encontrados por STAGGENBORG et al. (2000). Da 
mesma forma, DABERKOW et al. (1999) e BRYCESON et al. (1998) pesquisaram o uso de fotografias aéreas no milho irrigado e na soja, respectivamente, e ambos concluíram que o coeficiente de determinação entre as imagens e a produtividade do milho foi baixa. TAYLOR (1997) comenta que fotografias aéreas podem ser utilizadas com sucesso para mapear a distribuição do potencial de produtividade para grãos, porém utilizando a técnica de determinação de índice de vegetação para a realização da análise.

\section{CONCLUSÕES}

Os coeficientes de determinação existentes entre o valor digital de imagens e a produtividade de grãos, para células ou "pixels" de $25 \mathrm{~m}^{2}$ e $100 \mathrm{~m}^{2}$, são muito baixos, e com o aumento do tamanho das células há uma tendência de diminuição dos referidos valores.

As fotografias aéreas convencionais não podem ser utilizadas na previsão de produtividade, não sendo relevante a época de obtenção da fotografia para as culturas da soja e do milho.

O uso de câmeras $35 \mathrm{~mm}$, que atuem na faixa espectral do visível, sem a diferenciação das bandas que compõem tal faixa, não é viável para a estimativa de produtividade agrícola.

\section{AGRADECIMENTOS}

À FAPESP, Fazenda Lagoa Velha (Campos Novos Paulista - SP), Câmpus da USP de Pirassununga, New Holland, John Deere e Omnistar.

\section{REFERÊNCIAS}

BRYCESON, K.; MARVANEK, S. The role of satellite data and precision farming technologies for on-farm monitoring in Austrália. In: INTERNATIONAL CONFERENCE ON GEOESPATIAL INFORMATION IN AGRICULTURE AND FORESTRY DECISION SUPPORT, 1., [S.1.], 1998. Proceedings... [S.1.: s.n.], 1998. p.625-32.

COSTA, F.A.; SANTOS, M.L. Agricultura de Precisão - uma nova revolução tecnológica no campo. Economia Rural, Viçosa - MG, v.2, n.8, p.33, jul./set. 1997.

DABERKOW, S.G.; BRENEMAN, V.E.; KIM, C.S. Exploring the economic potetial of remotely sensed images: A case study of aerial photography in irrigated corn precision agriculture. In: EUROPEON CONFERENCE ON PRECISION AGRICULTURE CONGRESS CENTRE, 2., 1999, Denmark. Proceedings... Denmark: SCI Acadamic Press, 1999. p.615-24.

SCHUELLER, J.K. A review and integrating analysis of spatially - variable crop control of crop production. Fertilizer Research, Florida, v.33. p.1-34. 1992.

SENAY, G.B; WARD, A.D; LYON, J.G. Manipulation of high spatial resolution aircraft remote sensing data for use in site-specific farming. Transactions of the ASAE, St. Joseph, v.41, n.2, p.489-95, 1998.

STAGGENBORG, S.A.; FJELL, D.L.; TAYLOR. T. Using infrared images as a corn scouting tool. International Journal of Remote Sensing, London, v.7, p.90-116, 2000.

STEVEN, M.D.; MILLAR, C. Satellite monitoring for precision farm decision support. International Journal of Remote Sensing, London, v.4, p.325-34, 1997.

TAYLOR, J.C.; WOOD, G.A.; THOMAS, G. Mapping yield potential with remote sensing. EUROPEAN CONFERENCE ON PRECISION AGRICULTURE, 1., 1997, London. Proceedings... London: SCI, 1997. p.713-20. 